\title{
Yves Krumenacker, Boris Noguès (éd.), Protestantisme et éducation dans la France moderne
}

Lyon, LARHRA RESEA, Chrétiens et Sociétés, Documents et Mémoires $\mathrm{n}^{\circ}$ $24,2014,283 \mathrm{p}$.

Roland J. Campiche

\section{(2) OpenEdition}

\section{Journals}

Édition électronique

URL : http://journals.openedition.org/assr/28283

DOI : $10.4000 /$ assr.28283

ISSN : $1777-5825$

\section{Éditeur}

Éditions de l'EHESS

Édition imprimée

Date de publication : 31 décembre 2016

Pagination : 342

ISSN : 0335-5985

Référence électronique

Roland J. Campiche, "Yves Krumenacker, Boris Noguès (éd.), Protestantisme et éducation dans la France moderne », Archives de sciences sociales des religions [En ligne], 176 | octobre-décembre 2016, mis en ligne le 20 juillet 2017, consulté le 24 septembre 2020. URL : http://journals.openedition.org/ assr/28283 ; DOI : https://doi.org/10.4000/assr.28283

Ce document a été généré automatiquement le 24 septembre 2020.

(c) Archives de sciences sociales des religions 


\title{
Yves Krumenacker, Boris Noguès (éd.), Protestantisme et éducation dans la France moderne
}

\author{
Lyon, LARHRA RESEA, Chrétiens et Sociétés, Documents et Mémoires $\mathrm{n}^{\circ}$
} $24,2014,283 \mathrm{p}$.

Roland J. Campiche

\section{RÉFÉRENCE}

Yves Krumenacker, Boris Noguès (éd.), Protestantisme et éducation dans la France moderne, Lyon, LARHRA RESEA, Chrétiens et Sociétés, Documents et Mémoires $n^{\circ} 24$, $2014,283 \mathrm{p}$.

1 L'ouvrage couvre la période allant de la Réforme à la Révolution française, particulièrement celle marquée par l'Édit de Nantes et sa Révocation. Le protestantisme analysé s'inscrit dans la tradition zwinglienne-calvinienne, caractérisée par un programme éducatif impliquant une citoyenneté active. La Réforme de Zurich, après 1520 , se veut antimonarchique ou républicaine et anti-capitaliste, comme le remarque Daniel Tröhler dans son Pestalozzi, qui vient de paraitre en français. Dans les différents textes proposés aux lecteurs, on retrouve ces accents, mais modulés dans un contexte étroitement surveillé et régulé par un pouvoir royal catholique au fait de la menace représentée par "la religion prétendue réformée ». Une attention particulière au contexte socio-politique français est donc indispensable pour saisir la singularité du duopole protestantisme - éducation pris dans la tension entre l'exigence de proclamer le message de salut de la Réforme et de préserver par tous les moyens son institutionnalisation.

2 Dans leur texte introductif, les éditeurs se montrent très prudents quant au caractère spécifique de l'éducation protestante. Trop? Si l'humanisme potentiellement baigne l'entier du corps enseignant, Simona Negruzzo traite tout de même Sturm d'humaniste 
protestant, signifiant par cette appellation l'étroit rapport entretenu par le protestantisme avec les idées qui mettent en question non seulement la pédagogie, mais l'ordre social et religieux. L'analyse fouillée des «nouveaux abécédaires en français au XVI ${ }^{\mathrm{e}}$ siècle", conduite par Marianne Carbonnier-Burkard s'avère très significative sur ce dernier point. Par petites touches, elle montre la rupture opérée par le langage et les thèmes privilégiés avec la tradition catholique, ce qui provoque le tir de barrage du roi et de la machine judiciaire contre les abécédaires entre 1542 et 1559. L'auteur peut ainsi conclure que les abécédaires étaient devenus un modèle confessionnel.

3 La question de savoir si le protestantisme est porteur d'un modèle pédagogique spécifique est également controversée. Les Jésuites de l'époque considérée ont été aussi stimulés par les idées humanistes, ce qui explique que de nombreuses familles protestantes aient envoyé leurs enfants dans leurs écoles par choix ou nécessité, en raison de l'absence d'école protestante proche. La communication de Boris Noguès «Des huguenots chez les papistes » montre que pour le moins, sous le régime de l'Édit de Nantes, trois modes de fréquentation des écoles cohabitent chez les protestants: établissement jésuite, espace scolaire tenu par des laïcs où sont enseignés catholiques et protestants, malgré les réactions négatives des synodes protestants, et école protestante. Cette observation relativise les différences, mais attire aussi l'attention sur l'importance de la famille, comme l'illustre bien le texte de Julien Léonard sur "L'éducation de Jacques et Paul Couët du Vivier au XVII siècle ", et du catéchisme pour la socialisation confessionnelle. L'école n'est pas le seul vecteur d'intégration à une communauté particulière.

4 Revenons à l'hypothèse de l'innovation pédagogique. La réponse passe probablement le mieux par l'étude biographique. Dans "Jean Sturm et le gymnase de Strasbourg", Simona Negruzzo montre que ce maître a laissé une trace durable (l'établissement existe toujours!), ne serait-ce que par sa recherche d'un équilibre entre les connaissances empiriques et les principes théoriques, mais également par son affirmation que le but de l'éducation est de conduire à la foi, une foi mariant sagesse et éloquence. Plus loin dans le temps, Rabaut Saint-Étienne favorisera le passage de l'éducation religieuse à l'éducation nationale, selon l'intitulé du texte de Céline Borello qui ne voit rien de protestant dans la manière de penser l'éducation de la part de ce pasteur-politicien, mais bien dans les méthodes éducatives qu'il propose. Serait-il l'antithèse de Pestalozzi dont on cherche toujours aujourd'hui quelle fut sa méthode pédagogique, mais dont on sait qu'elle repose sur son fort attachement à la morale protestante. Il eut été intéressant de comparer les conceptions républicaines de ces deux "pédagogues" à l'origine confessionnelle semblable, mais marquée par des environnements et des influences théologiques différents. À noter que l'Assemblée nationale honora en 1792 Pestalozzi pour son soutien à la révolution par l'octroi de la nationalité française, bien que sa république vertueuse, sa marque protestante, ne correspondait pas exactement à la philosophie de la nouvelle république! Député à la Convention, Rabaut Saint-Étienne se fit finalement l'apôtre d'une éducation nationale sans dimension religieuse, situation qui prévaut toujours dans l'école publique française, malgré le développement des sciences sociales et humaines des religions.

5 Le livre comporte encore toute une série de monographies sur «Les collèges protestants au XvII siècle » (Yves Krumenacker), «Être collégien à Saumur sous l'Édit de Nantes» (Jean-Paul Pittion), «Le collège et l'académie de Saumur, un même 
établissement?" (Didier Boisson), "L'académie de Sedan et son insertion dans les réseaux d'enseignement français et européens » (Aurélien Behr). Ces textes éclairent à la fois les efforts titanesques du protestantisme français pour préserver son système de formation, pour maintenir en son sein les écoliers convoités ou séduits par « l'adversaire confessionnel » ainsi que pour illustrer et défendre l'identité protestante. Dans cette perspective, les académies de Saumur et de Sedan ont joué un rôle déterminant. On y voit l'étroitesse des relations entretenues avec les protestantismes européens (allemands, écossais, suisses, etc.) à la fois soutiens indéfectibles, refuges pour la formation des pasteurs et auteurs de nouveaux arguments en vue de la promotion du protestantisme.

6 Les communications de Chrystel Bernat («Armer les esprits ») et d'Amélie Lecoq ( Les catéchismes des pasteurs du désert ») nous font plonger dans l'enfer de la Révocation de l'Édit de Nantes. Ce génocide culturel avec ses massacres et enlèvements d'enfants pour les « recatéchiser » laissera une tache indélébile sur l'histoire de France. Face à la politique de destitution du protestantisme, les parades pour éviter le démantèlement d'un système éducatif apparaissent à la fois dérisoires et héroïques. On a là un exemple paradigmatique de la régulation par l'État, certes monarchique et non républicain, de la religion. En ce faisant, la France a fait l'économie d'un apprentissage de la gestion de la pluralité religieuse.

7 Dans ses conclusions, Willem Frijhoff, tout en soulignant la richesse des connaissances qu'il qualifie de textuelles, apportées par le colloque, en montre aussi la fragilité. La période prise en compte est en effet particulièrement longue et de ce fait inégalement couverte. Les sources s'avèrent souvent limitées et les risques de surinterpréter des trouvailles isolées réelles. Mais si ces restrictions paraissent fondées, on saluera l'importance de l'historiographie protestante et la continuité des recherches pour sortir cette histoire de l'ornière de l'oubli. Frijhoff, à juste titre, s'interroge in fine sur la spécificité réformée française en matière d'éducation. La persécution progressive, le contexte, pourrait bien constituer le facteur explicatif majeur. Dans une optique plus prospective, on aimerait en savoir plus sur l'héritage : de quel poids les réflexions protestantes françaises sur l'éducation ont-elles pesé sur la défense et l'illustration de la formation permanente dans les années 1960 et quel regard critique portent-elles sur le caractère très fonctionnel de la formation aujourd'hui, en particulier sur la formation continue? La recherche historique en modernité tardive a de beaux jours devant elle ! 